\title{
Artificial Intelligence and Automated Journalism: Contemporary Challenges and New Opportunities
}

\author{
Waleed ALI ${ }^{1 *}$, Mohamed HASSOUN ${ }^{2}$ \\ ${ }^{1}$ Lecturer, Department of Media, Tanta University, Egypt \\ ${ }^{2}$ Professeur des universités, ENSSIB de Lyon, France
}

*Corresponding Author: Waleed ALI, Lecturer, Department of MediaTanta University, Egypt

\begin{abstract}
Artificial intelligence (AI) is today an integral part of the new media ecosystem. As such, this, study aims to (1) describe the status quo of technology and its role in renewing and modernizing journalism, (2) give insights about the impact of artificial intelligence in changing journalism practice, (3) identify potential implications of artificial intelligence on the future of journalists, and (4) to extrapolate ethical and professional challenges that may upset the practices of the journalism profession. The study concludes that artificial intelligence technologies considered as the added value of journalism in the digital age, especially, its ability to overcoming the core problems faced by contemporary journalism, combating Fake news, news editing according to the editorial policy, as well as content personalization. The study found also that, artificial intelligence in journalism raise professional and ethical issues, notably; undermine creativity, the absence of monitoring, bias, transparency, fairness, data utilization, and data quality. It concluded also that artificial intelligence technologies will enhance, rather than replace, journalists' work. Hence, artificial intelligence does not pose a threat to professional journalism.
\end{abstract}

Keywords: Artificial intelligence, automated journalism, algorithm journalism, robot journalism, professional identity, journalism ethics.

\section{INTRODUCTION}

Recently, the media landscape has undergone rapid and unprecedented transformations, due to the significant advancement of Information and communication technologies (ICTs), which drive innovation [1] and continues unabated on one hand [2], along with its role in renewing and modernizing journalism on the other. Indeed, traditional media companies around the world are confronted by many challenges stemming from the radical digital transformation of the publishing industry [3]. Therefore, these companies are searching for new solutions to the challenges that the digital revolution has imposed on the news business [4]. As such, we have seen the rise of new mechanisms capable of conveying content to groups and individuals on an unprecedented speed, as well as shifting from one-way communication to interactive media.

Artificial intelligence (AI), algorithms, robots, and other technologies are today an integral part of the new media ecosystem. Therefore, several companies such as Minecraft, Facebook, Google, and Microsoft are investing today in artificial intelligence. In this context, AI presented a new media concept, that reflects a remarkable development in journalism, which known today as; "Robot Journalism" or "Algorithm journalism", or "Automated Journalism" as well. Indeed, when we talking about robots, we do not imagine them in front of a keyboard. They are in fact algorithms, programmed to transform data into texts.

Ultimately, the remainder of the paper is organized as follows. Section 2 describes the status quo of technology and its role in renewing and modernizing journalism. Section 3 outlines the background information about artificial intelligence and journalistic practice. I will briefly discuss the quantitative turn in journalism, along with the importance of automation system in newsrooms that have become an integral part of editorial work. Section 4 gives a general analysis of potential implications about the future of journalists, especially in the context of usage automatic AI processes into all aspects of news production and dissemination. Section 5 discusses the challenges of AI in journalism. Finally, the paper concludes with some conclusions. 


\subsection{Objectives}

The goal of the present research to (1) describe the status quo of technology and its role in renewing and modernizing journalism, (2) give insights about the impact of artificial intelligence in changing journalism practice, (3) identify potential implications of artificial intelligence on the future of journalists, and (4) to extrapolate ethical and professional challenges that may upset the practices of the journalism profession.

\subsection{Methodology}

The increasing dependence on artificial intelligence technologies in journalism at an unprecedented form highlights the importance of studying this phenomenon in depth. In this respect, this research based on a systematic review of the literature, that differs from a narrative review. While a narrative review provides an overview of the content available on a given topic, a systematic review is more narrowly focused and seeks to assemble, critically appraise or evaluate and synthesize the results of primary studies in an integrative approach.

\section{NEW TECHNOLOGIES AND JOURNALISM RENEWAL}

Technology has become a real driving force for the media sector to produce new digital content in line with the demands of Internet users. Hence, we can say that the dramatic changes in the field of journalism have connected directly to advanced technology tools [5]. In this context; some authors adopt a positive and optimistic view of the leading role of technology in the field of media and journalism. Thus, the use of AI technologies has become an indispensable part of the field of media that has to lead to radical transformations in the field of journalism [6]. In particular, this technology was seen as an objective alliance to change the professional practices of journalism, along with changing journalists' skills [7] and also has become an essential element of the requirement of contemporary newspaper production [8].

However, we can see that the technological transformations in the field of journalism are inextricably interwoven with the transformation of the media environment [9]. As Postman note, technologieswhich entail communication technologies, from writing to digital media-they generate environments that affect the everyday life of actors using them [10]. In sum, in the age of the media convergence, technological skills have become important in the journalism industry, which has transformed journalism by the digitalization of the work process in ways no one might have predicted even a few years ago.

\section{ARTIFICIAL INTELLIGENCE AND JOURNALISTIC PRACTICE}

\subsection{Quantitative Turn in Journalism}

The quantitative forms have become more prevalent in contemporary journalism [11]. Nevertheless, these new forms of journalism despite its relative novelty have drawn significant attention in academic literature and recently become the focus of considerable interest in the media sector. Loosen (2018) highlight of new four forms of journalism (see Figure 1), which can be considered as transformation process journalism faces today not only at the level of the basic stages of news production and consumption but also affects journalism at its core [12]:

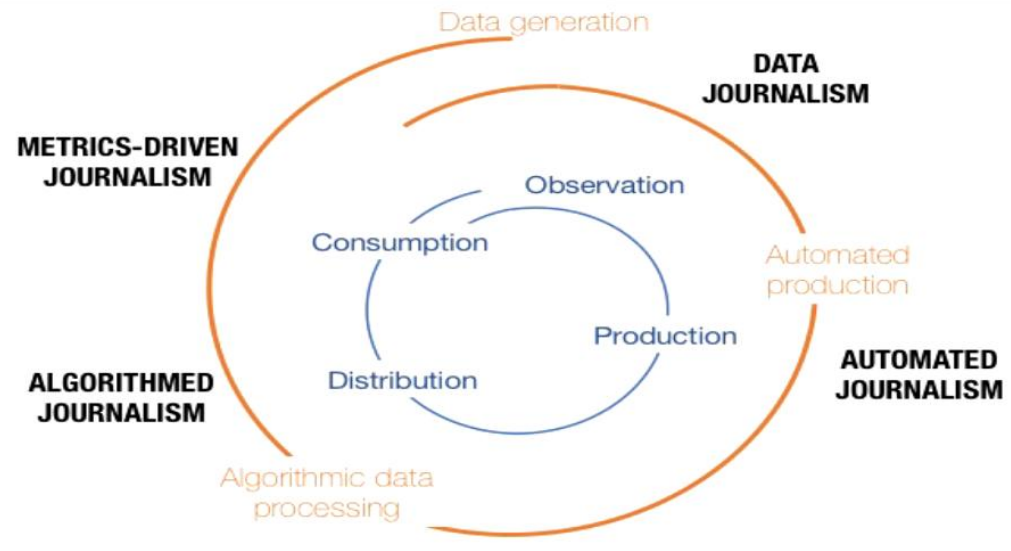

Figure1: Types of datafied journalism 
- Data journalism: This concept has gradually appeared in newsrooms over the last decade, which refers to the process of extracting useful information from data, writing articles based on the information and embedding visualizations in the articles that help readers to understand the significance of the story [13]. As Lindén (2017) notes, "digital revolution has expanded the supply and availability of data that can be used for computational journalistic processes, along with the expectation of events to a larger extent than before" (p. 24) [14]. However, data journalism represents the convergence of a number of fields which are significant in their own right - from investigative research and statistics to design and programming [15].

- Algorithm Journalism: This type of journalism defined as "the innovative processing that occurs at the intersection between journalism and data technology" [16]. Besides, it can be "the combination of algorithms, data, and knowledge from the social sciences to supplement the accountability function of journalism" [17].

- Automated Journalism: The focus with this term is to emphasize the increasing amount of content that is being produced automatically and by means of technologies being developed by providers of automated content solutions [18]. In other words, "algorithmic processes that convert data into narrative news texts with limited to no human intervention beyond the initial programming" [19].

- Metrics-Driven Journalism: Refers to the varied attempts to make sense of an ever-growing amount of audiences' digital traces with the potential to influence decision making processes at all stages of the news production process [20].

\subsection{Automation and Newsrooms}

There is no doubt that AI is gradually spreading through multi-creative spheres including journalismthat already has been impacted, especially in light of persistent economic disruption and the digital transformation [21]. In this respect, we can say that the evolution of artificial intelligence techniques radically reshaped newsrooms [22], specifically into all aspects of news production and dissemination as seen in the figure below [23]. Loosen (2018) pointed out that the technology facilitated by advances in the field of automated content production affects journalism at its very core: the production of news [24].

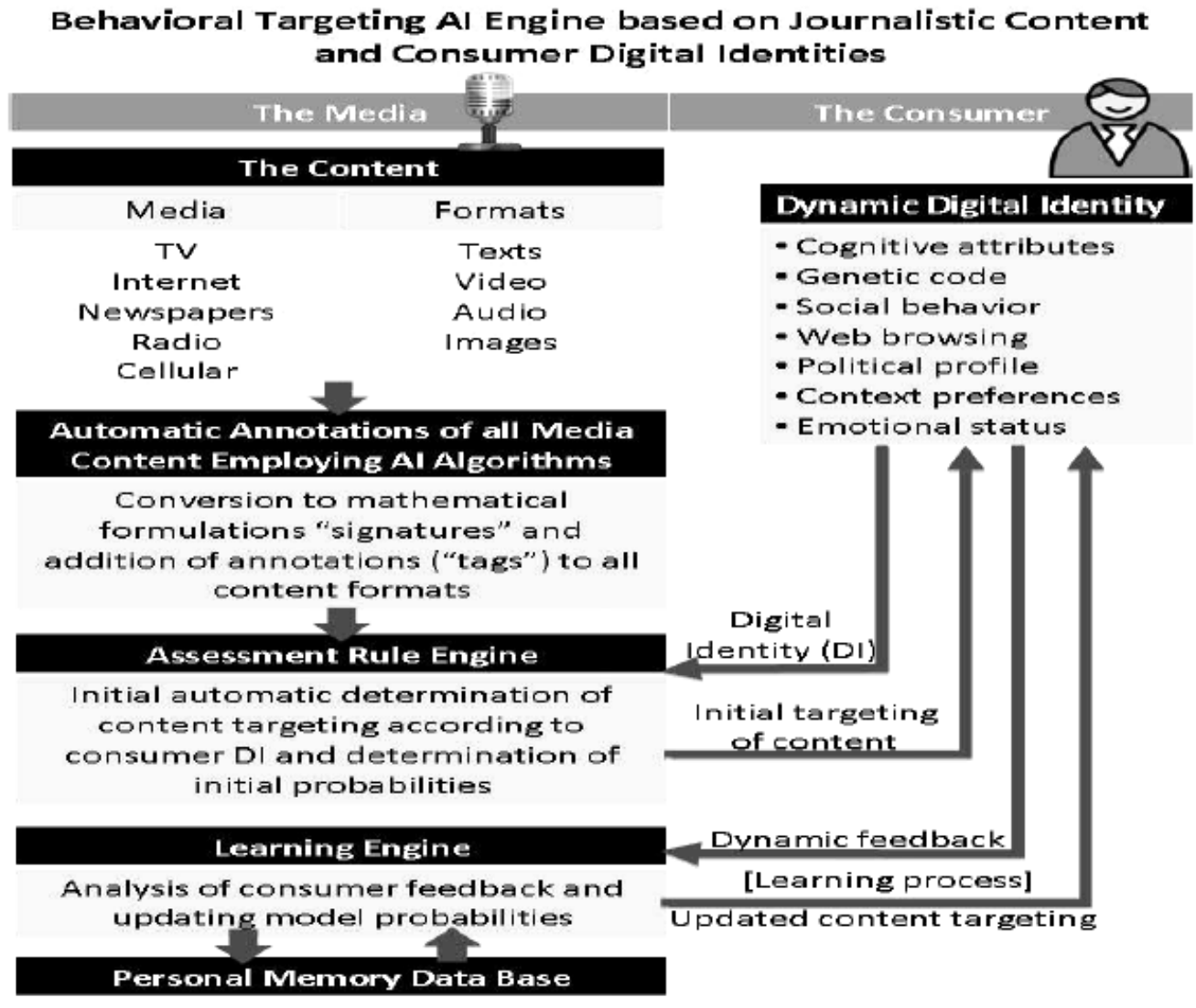

Figure2: Automatic newsroom 
Today, readers can read articles written entirely by a journalist who does not have a human form. In this context, the Washington Post has developed its own technology, an artificial intelligence called" Heliograph ", to support its editorial team during the 2016 Summer Olympics in Rio. Since then, the Washington Post has been using "Heliograph "to spit out 850 articles, which focused mainly on political and sports news.

In a recent Reuters report "Media, Trends and Technology Expectations in 2018", which included a survey of quite a few media outlets, nearly three-quarters of respondents said they use artificial intelligence in their production. On the other hand, they also develop projects to boost their use both in terms of content improvement, increased marketing efficiency and economic feasibility, automation of information validation within the information material, or to speed up the classification of information contained within a massive stream of data [25]. In 2017, Jung et al in the study entitled: Intrusion of software robots into journalism: The public's and journalists' perceptions of news written by algorithms and human journalists - pointed out that the audience tended to trust the journalistic materials written by software more than those written by journalists [26].

In sum, the relationship between technology and content creation in modern newsrooms is synthesized in the following basic idea: "This tendency in journalism proves the changing character of the newsroom staff, where programmers are working steadily more closely with journalists, and where journalists become programmers and vice versa" [27].

\section{Future of Journalists: Practical CONCERNS}

Recently, the journalistic landscape has undergone rapid and unprecedented transformations, due to artificial intelligence innovation. Unsurprisingly, then, this development raises questions about potential implications about the future of journalists, particularly with automated content production. As Carlson (2015) notes, "automated journalism harkens to the recurring technological drama between automation and labor present since the earliest days of industrialization" [28]. However, there is a diverse range of opinion on the issue that can be summarized in two main trends:

\subsection{First Trend: Pessimists}

According to this trend, journalism society, Today's is facing a number of potential challenges regarding jobs risks. As such, there are many practical concerns threaten the future of journalists, in particular with the context of the increasingly dominant role of algorithms in major news corporations and their consequent replacement of journalists by their non-human counterparts [29]. More profoundly, the need for a human presence in the newsroom is shrinking, which human reporters will no longer be the definitive source of news. In this context, authors concerns about the introduction of robots based on dismal scenarios [30], meaning the possibility of journalists simply losing their jobs, which entails large-scale unemployment in the near future is likely [31], as well as the pressures related to acquiring journalists of digital skills and learning programming [32].

Frey and Osborne (2013) pointed out that, about 47\% of total US jobs are at risk as a result of potential automation over the next decade or two [33]. Bernard (2013) state that, robot innovation, along with the availability of large data, is a powerful combination that can pose a real challenge to most jobs, including journalists [34]. On the other hand, Smith and Anderson (2014) found that robotics and artificial intelligence will permeate wide segments of daily life including journalism by 2025: "Journalists lost their jobs because of changes to advertising, professors are threatened by MOOCs [massive open online courses], and store salespeople are losing jobs to Internet salespeople. Improved user interfaces, electronic delivery (videos, music, etc.), and more self-reliant customers reduce job needs" (p. 6) [35].

\subsection{Second axis: Optimists}

Despite the growing use of artificial intelligence in news organizations, optimists argue that these technologies will enhance, rather than replace, journalists' work [36], implying that AI algorithms were not going to fully replace human journalists in newsrooms in the near future. As such, recent trends show that journalism still plays a crucial role in informing the people about the current events and thus artificial intelligence does not pose a threat to professional journalism. IBM Chief Executive Officer Ginni Rometty argues that the danger lies not so much in the number of jobs, but their changing character and complexity: "when it comes to complete job replacement, it will be a very small percentage; when it comes to changing a job and what you do, it'll be 100 percent" [37]. 
In sum, AI technology is an opportunity that reflects a remarkable development in the field of journalism, in particular, withdraw information from different sources and assemble them in the best possible way with fewer mistakes and bias on one hand, as well as produce news articles with high quality on the other[38].

\section{Challenges of Ai in JournalisM}

Despite media companies undergo dramatic changes due to the introduction of automatic AI processes into all aspects of news production and dissemination; understanding and addressing the professional and ethical issue is still at a very early stage. However, these issues are critical and need to be discussed.

\subsection{Professional Challenges}

\subsubsection{Undermine Creativity}

Indeed, creativity is the core concept in journalism [39] that reflects the human way of thinking including creative writing and interpreting, etc. In this respect, Latar (2018) notes, "AI algorithms cannot "think" out of the conceptual framework created for them by their human algorithm designers, they are unable of attaining the highest level of creativity that requires the ability to mentally cross into new unexpected conceptual frameworks" (p.24)[40]. For instance, AI algorithms cannot manufacture the requisite atmosphere to inspire readers' emotional reactions, such as laughter [41], respond to an accident scene, interviewing people on the street, or conducting any investigative work. Therefore, analytical skills and creativity still the major advantages of journalists against the algorithms [42].

\subsubsection{The absence of Monitoring}

Journalism is an essential force to maintain the survival of the social system, due to its great impact on society. Therefore, it is essential to preserve journalism as a public good in the digital age. As Latar (2018) notes, "AI algorithms cannot be expected to understand and monitor unexpected alarming developments: They lack the human capacity to make connections not previously experienced" [40].

\subsubsection{Bias}

The most significant challenge in the field of automated journalism is that biases can be created within AI systems, such as gender bias [43] and race bias [44]. From this perspective, AI algorithms are not free of human influence, implying that they are inherently influenced by the values of their designers. Osoba and Welser (2017) state that"The error and bias risk in algorithms and AI will continue as long as artificial agents play increasingly prominent roles in our lives and remain unregulated" (p.25) [45]. In 2015, Google had to apologize after the algorithms powering its Photos app tagged two black people as gorillas - perhaps because its training dataset did not have enough pictures of black people. In 2016, an investigation by ProPublica found that COMPAS "AI-driven software" that assesses the risk of criminals in the US was biased against people of color, in particular, black criminals, despite the fact that the white criminals had more serious criminal records [46].

\subsection{Ethical Challenges}

\subsubsection{Transparency}

This term essentially refers to being open about the way data is collected and used, as well as eschewing unnecessary data collection. However, transparency is very important to ensure reader trust, which would involve making the underlying data available - allowing people to interact with it. Leppänen, et al. (2017) defined transparency as the "trust in the system that transforms the data into an article" [47]. Thus, the publisher should first make the distinction between the subjects which items were written by a human journalist and which were written by a smart algorithm [48].

\subsubsection{Fact-Checking}

In this aspect, the readers should have information on how the raw data is chosen, which reasoning was employed while choosing the data, how the data was checked, whether personal data of the readers are being processed, how credibility and objectivity of the used sources are ensured [49].

\subsubsection{Fairness}

Fairness means to avoid harmful biases and stereotypes on people's lives. Thus, AI considered being the core challenge for journalism, in particular with the use of data as a tool for invading privacy, 
social manipulation and oppression. In October 2018, the International Conference of Data Protection and Privacy Commissioners (ICDPPC) released the Declaration on Ethics and Protection in Artificial Intelligence. The declaration states that "unlawful biases or discriminations that may result from the use of data in artificial intelligence should be reduced and mitigated".

\subsubsection{Data Utilization}

Currently, data utilization is one of the ethical problems related to AI in the field of automated journalism due to the lack of ad hoc laws and rules. Wang and Siau (2018) argue that the security and privacy of data pose significant risks not only for users but also for developers and governments [50]. Regarding this issue, Monti (2019) in his study entitled: Automated Journalism and Freedom of Information: Ethical and Juridical Problems Related to AI in the Press Field, point out that ethical duty should be the necessity to only use correct, objective, and accurate data [51].

\subsubsection{Data Quality}

One of the main bigger concerns of the current use of AI in newsrooms is the quality of the data used that can lead to misleading results, including the source and the accuracy of data. In this regard, the European Parliament (EP) has approved a report on Robotics which establishes an Ethical Code of Conduct, which includes several fundamental principles, notably; protect privacy and data use [52].

\section{CONCLUSION}

In general, journalism worldwide is undergoing a historic transition, thanks to rapid advancements in digital technology. Importantly, this development is another aspect of technological progress that had lead to major transformations in organizational structures and functions of media companies. In this respect, artificial intelligence algorithms considered the most important revolution of journalism in the digital age, which has been reorganized the newsroom as never before. On the other hand, these technologies offer much great potential for enhancing journalism today - especially allow journalists to process a high volume of data in a limited period of time, create news stories from structured data and automatically deliver them, as well as more diverse coverage.

In sum, artificial intelligence does not pose a threat to professional journalism. In other words, artificial intelligence technologies considered as the added value of journalism in the digital age, which cannot completely replace journalists, implying that these technologies will enhance, rather than replace, journalists' work. Some of the key points can be summarized as follows.

\subsection{Overcome Challenges of Contemporary Journalism}

Artificial intelligence (AI) has changed the way journalists interact with the world outside the newsroom, as well as easier to manage editorial tasks [14]. On the other hand, AI enables journalists to analyze data from multiple sources, besides conversion of spoken words into texts, texts conversion to audio and video, as well as analysis of the images and its classification. In sum, we can say that artificial intelligence will help journalists to survive and overcome the core problems faced by contemporary journalism including (1) the overabundance of information and sources; (2) the credibility and falling trust; and (3) the business model crisis [53], in order to continue delivering "quality journalism".

\subsection{Combating Fake news}

The phenomenon of fake news and misinformation is one of the most important challenges, facing journalists at present. Therefore, the use of smart software, in particular, journalistic algorithms has become imperative to identify fake news on the one hand, as well as enhance news quality and accuracy on the other [54]. Software such as Factmata1 is building expert contextual artificial intelligence to reduce misinformation and abusive content online. Kalina Bontcheva2 (2018) created a system to help address the challenges of misinformation and to automatically verify online rumors and thereby allow journalists, to check the veracity of stories on social media platforms. The findings

\footnotetext{
${ }^{1}$ Factmata aims to build a "trust score" for online content in real time, by creating an artificial intelligence assisted tool for everyday internet users to verify content.

${ }^{2}$ Professor KalinaBontcheva, who conceived and led the Pheme research project to identify and verify rumors on social media, www.pheme.eu, accessed 21 Feb 2019.
} 
of the study conducted by Graves (2018) found that automated fact-checking can help journalists to identify and verifying misinformation across the media landscape and to respond as quickly as possible as seen in the figure below [55].

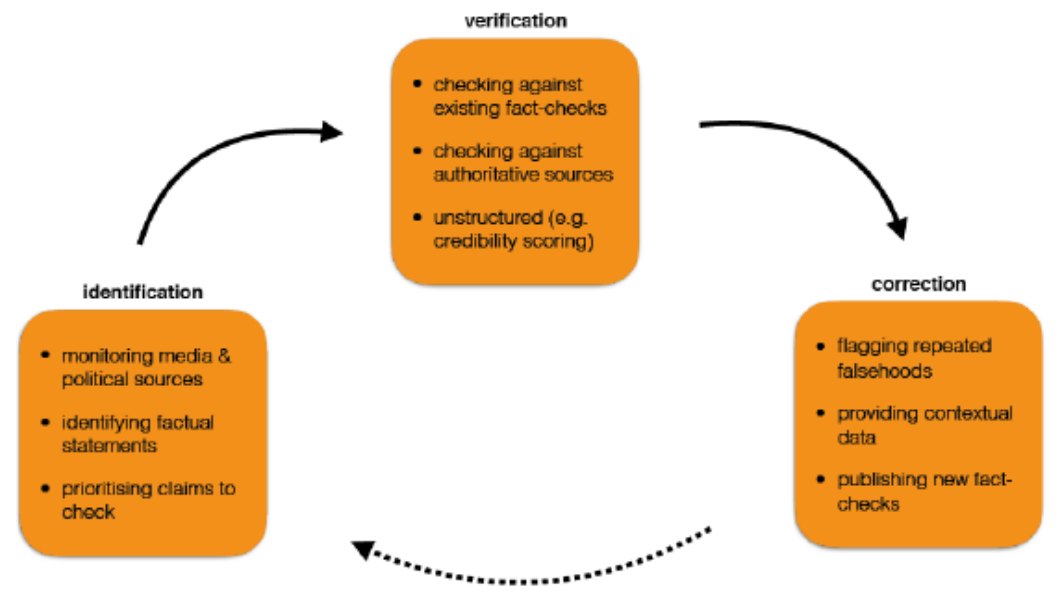

Figure3: Automated fact-checking

\subsection{News editing according to the editorial policy}

Artificial intelligence techniques have the advantage of relieving the journalist of routine work as much as possible [56], and perhaps one of these works is to rephrase the story to fit the editorial policy of each medium. Indeed, there is software available that gathers news from a large number of different sources and rephrases it in line with the editorial policy of each organization, without any human effort, such as Urbs, which the Associated Press uses to distribute some news. Johnston and Forde (2017) pointed out that the new technologies "have the potential to significantly impact on news gathering and assembling routines, as well as editorial decisions regarding repurposing content" [57].

\subsection{Content Personalization}

In recent times, AI has been rolled out with spectacular speed in an increasing number of media companies. As such, there has been a major shift in the way that these companies interact with their users. Hence, AI is the opportunity for users to create their personalized news agenda, as well as the possibility to generate news in multiple languages and therefore to reach a broader audience and new markets [58]. However, personalization in general means making content personal, relevant, and therefore, more favorable for the consumers [59]. In this respect, Smith and Linden (2017) showed that filtering algorithms capable collect, sort and prioritize data about the users' behavior [60]. In 2017, some scholars conducted a study entitled: PersaLog: Personalization of News Article Content they introduced the PersaLog system for journalism professionals which able to content personalization, as well as enhance learning and behavioral changes in readers and increase engagement [61]. In sum, news sites today can be offering everything most users need by using "cookies", such as personalized content by register different information from real uses of users while they act on the given website [62].

\section{ACKNOWLEDGEMENTS}

Authors are highly thankful to Egyptian Government and Tanta University under the chairmanship of Dr. Magdy Sabaa and Dr. Mustafa El Sheikh, Vice-President for Graduate Studies and Research for providing financial assistance and ENSSIB for providing necessary infrastructure to carry out the research work.

\section{REFERENCES}

[1] Dierickx, L. (2018). Du statute d'objet technique à Celui d'objet social dans le contexte de la production automatisée d'informations journalistiques. Terminal, 122. Retrieved from http://journals.openedition.org/ terminal/1964[Accessed: $10^{\text {th }}$ January 2019].

[2] Wölker, A. \& Powell, TE. (2018). Algorithms in the newsroom? News readers' perceived credibility and selection of automated journalism. Journalism, 1-18. Retrieved from https://doi.org/10.1177/1464884918 757072 [Accessed: $21^{\text {th }}$ January 2019]. 
[3] Leppanen, L., Munezero, M., Granroth-Wilding, M. \& Toivonen, H. (2017). Data-Driven News Generation for Automated Journalism. Proceedings of the $10^{\text {th }}$ International Conference on Natural Language Generation. Santiago de Compostela, Spain, September 4-7, p188-197. Retrieved from http:// aclweb.org/anthology/W17-3528 [Accessed: 12 ${ }^{\text {th }}$ October 2018].

[4] Marconi, F. \& Siegman, A. (2017). The Future of Augmented Journalism: A guide for newsrooms in the age of smart machines. Associated Press.

[5] Veglis, A. \& Bratsas, C. (2017). Towards a taxonomy of data journalism. Journal of Media Critiques, 3(11), 109-121.

[6] Galily, Y. (2018). Artificial intelligence and sports journalism: Is it a sweeping change? Technology in Society, 54, 47-51.

[7] Örnebring, H. (2016). Newsworkers: A comparative European perspective. London: Bloomsbury Academic.

[8] Zangana, A. (2017). The impact of new technology on the news production process in the newsroom. $\mathrm{Ph} . \mathrm{D}$. Thesis. The University of Liverpool.

[9] Hepp, A. \& Loosen, W. (2018). Makers of future journalism? The role of pioneer journalists and pioneer communities in transforming journalism. Bremen: "Communicative Figurations" Research Network, Centre for Media, Communication, and Information Research (ZeMKI) (Working Paper Series "Communicative Figurations Working Papers" No.19).

[10] Velasquez, A., Renó, D., Beltrán, AM., Maldonado, JC. \& León, CO. (2018). From the mass media to social media: reflections on the new media ecology. Revista Latina de Comunicación Social, 73, 583 594.

[11] Coddington, M. (2015). Qualifying Journalism's Quantitative Turn: A typology for evaluating data journalism, computational journalism, and computer-assisted reporting. Digital Journalism, 3(3), 331-348.

[12] Loosen, W. (2018). Four Forms of Datafeed Journalism: Journalism's Response to the Datafication of Society. Bremen: "Communicative Figurations" Research Network, Centre for Media, Communication, and Information Research (ZeMKI) (Working Paper Series "Communicative Figurations Working Papers" No.18).

[13] Veglis, A. \& Bratsas, C. (2017). Towards a taxonomy of data journalism. Journal of Media Critiques, 3(11), 109-121.

[14] Lindén, C-G. (2017). Algorithms for journalism: The future of news work. The Journal of Media Innovations, 4(1), 60-76. Retrieved from https://journals.uio.no/index.php/TJMI/article/view/2420 [Accessed: $12^{\text {th }}$ October 2018].

[15] Bradshaw, P. (2010). How to Be a Data Journalist. The Guardian, 1(10). Retrieved from https://www. The guardian.com/news/datablog/2010/oct/01/datajournalism-how-to-guide [Accessed: $11^{\text {th }}$ December 2018].

[16] Gynnild, A. (2014). Journalism innovation leads to innovation journalism: The impact of computational exploration on changing mindsets. Journalism, 15 (6), 713-730.

[17] Hamilton, JT. \& Turner, F. (2009). Accountability through Algorithm: Developing the Field of Computational Journalism. Behavioral Sciences Summer Workshop, Stanford. Retrieved from http://web. stanford.edu/ fturner/Hamilton\%20Turner\%20Acc\%20by\%20Alg\%20Final.pdf/[Accessed: $11^{\text {th }}$ July 2018].

[18] Graefe, A. (2016). Guide to Automated Journalism. Tow Center for Digital Journalism. Retrieved from http://towcenter.org/research/guide-to-automated-journalism/[Accessed: $19^{\text {th }}$ August 2018].

[19] Carlson, M. (2015). The Robotic Reporter: Automated journalism and the redefinition of labor, compositional forms, and journalistic authority. Digital Journalism, 3(3), 416-431.

[20] Tandoc, EC. \& Thomas, RJ. (2015). The ethics of web analytics. Implications of using audience metrics in news construction. Digital Journalism, 3(2), 243-258.

[21] Newman, N., Fletcher, R., Kalogeropoulos, A., Levy, DA. \& Nielsen, R.K. (2018). Reuters Institute Digital News Report 2018. Oxford: Reuters Institute for the Study of Journalism.

[22] Galily, Y. (2018). Artificial intelligence and sports journalism: Is it a sweeping change? Technology in Society, 54, 47-51.

[23] Latar, NL. (2015).The Robot Journalist in the Age of Social Physics: The End of Human Journalism? The New World of Transitioned Media, 65-80.

[24] Loosen, W. (2018). Four Forms of Datafeed Journalism: Journalism's Response to the Datafication of Society. Bremen: "Communicative Figurations" Research Network, Centre for Media, Communication, and Information Research (ZeMKI) (Working Paper Series "Communicative Figurations Working Papers" No.18).

[25] Newman N. (2018). Journalism, Media, and Technology Trends and Predictions. Digital news project. Retrieved from https://reutersinstitute.politics.ox.ac.uk/our-research/journalism-media-and-technologytrends-and-predictions-2019 [Accessed: $15^{\text {th }}$ January 2019]. 
[26] Jung, J., Song, H., Kim, Y., Im, H. \& Oh, S. (2017). Intrusion of software robots into journalism: The public's and journalists' perceptions of news written by algorithms and human journalists. Computers in Human Behavior, 71, 291-298.

[27] Zangana, A. (2017). The impact of new technology on the news production process in the newsroom. Ph.D. thesis, University of Liverpool. Retrieved from https://livrepository.liverpool.ac.uk/3008664/ [Accessed: $17^{\text {th }}$ December 2018].

[28] Carlson, M. (2015). The Robotic Reporter: Automated journalism and the redefinition of labor, compositional forms, and journalistic authority. Digital Journalism, 3(3), 416-431.

[29] Kirley, E. (2016). The robot as cub reporter: law's emerging role in cognitive journalism. European Journal of Law and Technology, 17 (3). Retrieved from http://ejlt.org/article/view/457/694[Accessed: $11^{\text {th }}$ July 2018].

[30] Kim, D., \& Seongcheol, K. (2018). Newspaper Journalists' Attitudes toward Robot Journalism. Telematics \& Informatics, 35(2), 340-357.

[31] Coombs, CR., Hislop, D., Barnard, S. \& Taneva, S. (2017). Impact of artificial intelligence, robotics and automation technologies on work - rapid evidence review. Retrieved from https://www.researchgate.net/ publication/323826787 [Accessed: $16^{\text {th }}$ October 2018].

[32] Pashevich, E. (2018). Automation of news production in Norway: Augmenting newsroom with artificial intelligence. MA thesis. The University of Oslo, Faculty of Humanities, Department of Media \& Communication. Retrieved from https://www.duo.uio.no/handle/10852/63213 [Accessed: $19^{\text {th }}$ January 2019].

[33] Frey, CB. \& Osborne, MA. (2013). The Future of Employment: How Susceptible are Jobs to Computerisation? Working Paper, Oxford Martin Programme on the Impacts of Future Technology. Retrieved from http://www.oxfordmartin.ox.ac.uk/downloads/academic/future-of-employment.pdf [Accessed: $14^{\text {th }}$ July 2018].

[34] Bernard, M. (2013). Big Data and Robots - Together They Might Challenge You for Your Job. KPI Library. Retrieved from http://kpilibrary.com/topics/big-data-and-robots-together-they-might-challengeyou-for-your-job [Accessed: $25^{\text {th }}$ August 2018].

[35] Smith, A. \& Anderson, J. (2014). AI, robotics, and the future of jobs. Pew Research Center. Retrieved from http://www.pewinternet.org/2014/08/06/future-of-jobs/ [Accessed: $12^{\text {th }}$ February 2019].

[36] Hansen, M., Roca-Sales, M., Keegan, J., King, G. (2017). Artificial Intelligence: Practice and Implications for Journalism. Tow Center for Digital Journalism, Columbia University. Retrieved from https://doi.org/10.7916/D8X92PRD [Accessed: 10 ${ }^{\text {th }}$ December 2018].

[37] Cao, J. (2017). IBM's Rometty Sees AI Changing, Not Eliminating, Future Jobs. Bloomberg. Retrieved from https://www.bloomberg.com/news/articles/2017-09-13/ibm-s-rometty-sees-ai-changing-not-eliminating-futurejobs [Accessed: $18^{\text {th }}$ November 2018].

[38] Galily, Y. (2018). Artificial intelligence and sports journalism: Is it a sweeping change? Technology in Society. 54, 1-5. Retrieved from https://doi.org/10.1016/j.techsoc.2018.03.001 [Accessed: $23^{\text {th }}$ January 2019].

[39] Malmelin, M. \& Nivari-Lindström, L. (2015). Rethinking creativity in journalism: Implicit theories of creativity in the Finnish magazine industry. Journalism, 18(3), 334-349. Retrieved from https://doi.org/10. 1177/1464884915620272 [Accessed: $11^{\text {th }}$ July 2018].

[40] Latar, NL. (2018). Robot Journalism: Can Human Journalism Survive? World Scientific Publishing Company.

[41] Aljazairi, S. (2016). Robot journalism: threat or an opportunity. MA thesis. Örebro University, School of Humanities, Education and Social Sciences. Retrieved from http://oru.diva-portal.org/smash/record. jsf?pid=diva2\%3A938024\&dswid=5523[Accessed: $23^{\text {nd }}$ September 2018].

[42] Van Dalen, A. (2012). The Algorithms Behind the Headlines: How Machine-written News Redefines the Core Skills of Human Journalists. Journalism Practice, 6, 648-658. Retrieved from http://dx.doi.org/10. 1080/17512786.2012.667268 [Accessed: $11^{\text {th }}$ April 2018].

[43] Larson, B. N. (2017). Gender as a variable in natural-language processing: Ethical considerations. Proceedings of the First Workshop on Ethics in Natural Language Processing, pp. 1-11, Valencia, Spain.

[44] Koolen, C. \& van Cranenburgh, A. (2017). These are not the Stereotypes You are Looking For: Bias and Fairness in Authorial Gender Attribution. Proceedings of the First ACL Workshop on Ethics in Natural Language Processing. pp. 12-22, Valencia, Spain.

[45] Osoba, OA. \& Welser, W. (2017).An Intelligence in Our Image: The Risks of Bias and Errors in Artificial Intelligence - RAND Corporation. Retrieved from https://www.rand.org/pubs/research_reports/RR1744. html [Accessed; $17^{\text {th }}$ September 2018].

[46] Angwin, J, Larson, J., Mattu, S. \& Kirchner, L. (2016). Machine Bias. There's software used across the country to predict future criminals. And it's biased against blacks. ProPublica. Retrieved from 
https://www.propublica.org/article/machine-bias-risk-assessments-in-criminal-sentencing [Accessed: $16^{\text {th }}$ October 2018].

[47] Leppänen L., Munezero, M., Granroth-Wilding M., \& Toivonen, H. (2017). Data-Driven News Generation for Automated Journalism. Proceedings of the $10^{\text {th }}$ International Conference on Natural Language Generation, 188-197. Retrieved from https://aclanthology.info/papers/W17-3528/w17-3528[Accessed: $18^{\text {th }}$ August 2018].

[48] Ombelet, PJ., Kuczerawy, A. \& Valcke P. (2016). Employing Robot Journalists: Legal Implications, Considerations, and Recommendations. WWW 2016 Companion, April 11-15, Montréal, Québec, Canada.

[49] Clerwall, C. (2014). Enter the Robot Journalist: Users' perceptions of automated content. Journalism Practice, 8(5), 519-531.

[50] Wang, W., \& Siau, K. (2018).Ethical and Moral Issues with AI: A Case Study on Healthcare Robots. Twenty-fourth Americas Conference on Information Systems. Retrieved from https://www.researchgate. net/publication/325934375[Accessed: $18^{\text {th }}$ January 2019].

[51] Monti, M. (2019). Automated Journalism and Freedom of Information: Ethical and Juridical Problems Related to AI in the Press Field. Retrieved from https://papers.ssrn.com/sol3/papers.cfm?abstract_id = 3318460 [Accessed: $19^{\text {th }}$ February 2019].

[52] European Parliament (2017). Report with Recommendations to the Commission on Civil Law Rules on Robotics. Retrieved from http://www.europarl.europa.eu/doceo/document/A-8-2017-0005_EN.html [Accessed: 20 ${ }^{\text {th }}$ August 2018].

[53] Beckett, C. (2018). Journalism and artificial intelligence: some notes. Retrieved from https: //blogs. lse.ac.uk/mediapolicyproject/2018/03/02/journalism-and-artificial-intelligence-some-notes/[Accessed: $17^{\text {th }}$ January 2019].

[54] Graefe, A., Haim, M., Haarmann, B. \& Brosius, H.-B. (2016). Readers' perception of computer-generated news: Credibility, expertise, and readability. Journalism, 1-16. Retrieved from https://doi.org/10.1177/ 1464884916641269 [Accessed: $11^{\text {th }}$ July 2018].

[55] Graves, L. (2018).Understanding the Promise and Limits of Automated Fact-Checking. Retrieved from https://reutersinstitute.politics.ox.ac.uk/sites/default/files/2018-02/graves_factsheet_180226\%20FINAL.pdf [Accessed: $23^{\text {th }}$ January 2019].

[56] Graefe, A. (2016). Guide to Automated Journalism. Tow Center for Digital Journalism. Retrieved fromhttp://towcenter.org/research/guide-to-automated-journalism/ [Accessed: $19^{\text {th }}$ September 2018].

[57] Johnston, J., \& Forde S. (2017). Churnalism. Digital Journalism, 5(8), 943-946. Retrieved from https://doi.org/10.1080/21670811.2017.1355026 [Accessed: $22^{\text {th }}$ October 2018].

[58] Dörr, K. (2016). Mapping the field of Algorithmic Journalism. Digital Journalism, 4(6), $700-722$. Retrieved from https://doi.org/10.1080/21670811.2015.1096748 [Accessed: $19^{\text {th }}$ November 2018].

[59] Pashevich, E. (2018). Automation of news production in Norway: Augmenting newsroom with artificial intelligence. Master's Thesis in Nordic Media. Department of Media \& Communication. Faculty of Humanities. The University of Oslo. Retrieved from https://www.duo.uio.no/handle/10852/63213 [Accessed: $24^{\text {th }}$ January 2019].

[60] Smith, B., \& Linden, G. (2017). Two Decades of Recommender Systems at Amazon. Com. IEEE Internet Computing. Retrieved from https://ieeexplore.ieee.org/document/7927889 [Accessed: $11^{\text {th }}$ August 2018].

[61] Adar, E., Gearig, C., Balasubramanian, A. \& Hullman, J. (2017). PersaLog: Personalization of News Article Content. Proceedings of the $2017 \mathrm{CHI}$ conference on Human Factors in Computing Systems, Denver, Colorado, US, May 06-11, 2017. Retrieved from http://dx.doi.org/10.1145/_3025453. 3025631[Accessed: 26 ${ }^{\text {th }}$ August 2018].

[62] Pariser, E. (2011). The Filter Bubble: What The Internet Is Hiding From You. Penguin UK.

Citation: Waleed ALI, Mohamed HASSOUN. "Artificial Intelligence and Automated Journalism: Contemporary Challenges and New Opportunities". International Journal of Media, Journalism and Mass Communications (IJMJMC), vol 5, no. 1, 2019, pp. 40-49. doi:http://dx.doi.org/10.20431/2455-0043.0501004

Copyright: (c) 2019 Authors. This is an open-access article distributed under the terms of the Creative Commons Attribution License, which permits unrestricted use, distribution, and reproduction in any medium, provided the original author and source are credited. 